\title{
Robustness as an image of sustainability: applied conceptualisations and their contribution to sustainable development
}

\author{
Douwe M. de Goede ${ }^{1}$, Bart Gremmen ${ }^{1}$ and Margaretha Blom-Zandstra ${ }^{2}$ \\ ${ }^{1}$ Wageningen University, Centre for Methodical Ethics and Technology Assessment, P.O. Box 8130, 6700 EW Wageningen, the \\ Netherlands; douwe.degoede@wur.nl \\ ${ }^{2}$ Wageningen University \& Research Centre, Plant Sciences Group, P.O. Box 16, 6700 AA Wageningen, the Netherlands
}

\begin{abstract}
Sustainability is a catch-all term in need of more tangible, yet qualitatively measureable operationalisations. This paper discusses the relevance of robustness as an image of sustainability. We argue that robustness has conceptual advantages against sustainability because it is embedded in system thinking and gives direction to operationalisations of sustainable development more than sustainability ever can. We consider conceptualisations of robustness in three TransForum projects which were set up to develop the concept of robustness in agricultural innovation. In these projects, robustness is conceptualised from an engineering perspective in relation to system efficiency and control. We suggest a frame of reference based on two organising principles, and suggest that other conceptualisations of robustness should be taken into account when operationalising sustainable development through robustness.
\end{abstract}

Keywords: system thinking, stability, resilience, conceptual analysis

\section{Introduction}

The TransForum program (Van Latesteijn and Andeweg, 2011) was initiated in 2004 to stimulate Agro innovation for sustainable development. As the type of innovation aimed for was argued to transcend the normal operational impact of innovations, the program called for new mindsets to 'do better things', rather than 'doing things better' (Van Latesteijn and Andeweg, 2011). The program rejected the prevailing focus on improving efficiency and urged for an agricultural reinvention in which sustainable development would be an innovation target. TransForum used sustainability and sustainable development from a triple bottom-line (3BL) perspective, focussing on the triple $P$-values people, planet and profit. The $3 \mathrm{BL}$ approach is the most accessible and most applied method to evaluate sustainability. Although to some extent the 3BL narrows down the methods of constituting sustainability as an object of science, it also contributes to many different operationalisations of sustainability and lengthy debates about their appropriateness. As a consequence, triple P-sustainability and triple-P sustainable development must be understood as catch-all terms, rather than as clear innovation targets which can contribute to purposeful reinventions of agricultural practises. We therefore believe that more tangible, yet qualitatively measureable, images of sustainability are needed: operationalisations of sustainability that include shared normative values and can shape mindsets to 'doing better things'.
In this paper we consider one of these, namely robustness: a concept that has rapidly gained attention as a possible solution for a variety of sustainability problems which characterise modern agriculture. In reaction to experienced increases in vulnerability to unwanted fluctuations, Ten Napel et al. (2006) suggested that agricultural systems should be made more robust. However, we have observed that the term is used loosely in various contexts and that it has been given equally diverse meanings.

Although robustness and sustainability are both intuitively attractive, contested concepts, robustness has several conceptual advantages over sustainability:

- the disturbances against which systems develop robustness are disturbances that can potentially harm the system structurally, or functionally, and should therefore be seen as sustainability problems; robustness thus gives direction to potential solutions to sustainability problems, i.e. a contribution to the operationalisation of sustainable development in practice.

- robustness is embedded in system thinking - a perspective which focuses on interactions of the element being studied with other elements with which it forms a system (Aronson, 1996); a discussion of system robustness is relevant only when, and subsequently requires that, both system feature and potential thread are specified (Jen, 2005; Lesne, 2008). As a consequence, a description of system robustness relates to a strategy to cope with a specific thread and ideally not only 
specifies what is robust to what, but ultimately also how. From an engineering perspective, the latter is of strategic importance to operationalise sustainability.

Three scientific research projects which were started within the TransForum program more or less conceptualised robustness through the selection of inventions directed at sustainability of specific production systems. These projects were:

1. 'Stacking functionality expressed in apple genes'. The aim of this project was the development of high-quality apple varieties that have a durable resistance to apple scab (Venturia inaequalis) by means of cisgenesis.

2. 'A monitoring and control system for conditioning of plants and greenhouses'. The project aimed to quantify physiological effects of climate conditions on plants in energy efficient and energy producing greenhouses, and develop intelligent crop monitoring systems of plant performance.

3. 'Robustness of animal production systems'. The main objective of this project was to develop the concept of robustness of animal production systems at various levels using system and control theory and apply these concepts to cases in the production system (farm), the production chain and at regional level.

In this paper we present a framework against which we assess the robustness conceptualisation of the abovementioned projects.

For this purpose, we shortly introduce the three projects, explore the conceptualisation of robustness in each project and use these results to discuss suitable and less suitable conceptualisations in the context of sustainable agriculture. We aim to show which operationalisation of robustness is dominant in the context of sustainable agriculture, and which alternative operationalisations might be worth considering. In other words, which problems and potential benefits are associated with the different conceptualisations? First, we introduce two organising principles to distinguish four potential conceptualisations of robustness. We will use this framework in our analysis of robustness conceptualisation used in the three TransForum projects.

\section{From sustainability to robustness: a new mindset?}

Implicitly, robustness has been an issue of concern in various agri-businesses, but as a concept, it has particularly been discussed in animal husbandry, where it is typically narrowed to physiological, behavioural and immunological performance. Conceptualised at the animal level it is mainly used to refer to an animal's ability to maintain homeostasis in increasingly dynamic environments and the capacity to adapt successfully to changing environmental management and health conditions (Kanis et al., 2004, 2005; Klopčič et al., 2009; LNV, 2007; Star et al., 2008; Ten Napel et al., 2006). At livestock system level, robustness has emerged as a design criterion for housing systems, signifying much the same as the flexibility to change (WUR, 2004). At the genetic level, phenotypic robustness, also called phenotypic buffering or canalisation (Levy and Siegal, 2008; Scharloo, 1991; Waddington, 1953), rather denotes the invariance of phenotypes in the face of both genetic and environmental perturbations. Robustness has also been related to performance under poor production environments (Sall et al., 1998); to production potential in a wide variety of environmental conditions (Knap, 2005); strategic decisionmaking in the context of unknown futures (Cittadini et al., 2008) and capacities to respond to crop failures (Lien et al., 2007). Still, the meaning of robustness in different agricultural contexts as well as its justification vis-à-vis current transition processes towards more sustainable and socially acceptable agriculture remains unclear.

In this paper we argue that these different conceptualisations of robustness are not so much related to different disciplines, but rather to different views of systems. The basic components of such systems - input, throughput, output and environment - have all been related to robustness. This is not surprising, since robustness is embedded in system thinking. From a system perspective, robustness may well be a prerequisite for existence. On the other hand, we do not consider all systems to be equally robust. When attempting to assess system robustness, it is precisely this subjectivity which explains the need to make explicit how specific system features cope with specific threats. These specifications are preceded by contentious visualisations of the system under consideration, its boundaries, and the environment in which it operates. In the next section, we use two organising principles to construct dimensional descriptions which classify different conceptualisations of robustness.

\section{Organising principles}

A specification of the features and perturbations of a system gives rise to different views of the stability and behaviour of the system in relation to its environment. We argue that different stability views, different understandings of a system's behaviour and to a lesser extent perceptions of the system environment are organising principles in a theoretical classification of conceptualisations of robustness. We discuss each principle below. 


\section{Stability view}

System stability can qualitatively refer to the efficiency of execution, or quantitatively to the presence of a certain functionality. Robustness then refers either to the efficiency of function, or to the persistence of functionality (see also (Holling and Gunderson, 2002; Jen, 2005; Kitano, 2007). The first relates stability to system performance in the vicinity of a desired steady state. In this view, robustness refers to the capacity of a system to withstand perturbations and to stabilise a steady state of optimised efficiency. We will refer to this view as the 'efficiency of function' perception of robustness. Efficiency of function perceptions of robustness are common when system functions are related to qualitative or quantitative output levels. Robustness is then measured in terms of sensitivity, resistance or rate of return. In agricultural contexts, efficiency of function perceptions of robustness include for instance water use efficiency aspects of drought tolerance, disease resistance and the ability to recover from stress.

The second way of looking at system stability assumes that systems have multiple steady states; these being mainly found in descriptions of socio-ecological systems (Levin and Lubchenco, 2008; Walker et al., 2005). Rather than defining robustness as the ability to keep the system in an steady state of optimised efficiency, robustness as persistence refers to the capacity to maintain a particular state of balance, i.e. to persist in one configuration, rather than another. We will call this view the 'persistence of functionality' conceptualisation of robustness.

Robustness as this persistence of functionality is expressed as a magnitude of disturbance that a system can withstand before it moves to an alternative steady state. Consider for instance food webs, the robustness of which can gradually decline due to biodiversity loss, thereby reducing equilibrium stability and increasing the chances of transitions to alternative steady states (Gilbert, 2009).

\section{System behaviour}

Different views of the relation between a system and its environment lead to different views of robustness. In general, this distinguishes two bipolar views of the ability of systems to cope with disturbances. Systems are assumed to be either in essentially stable or essentially unstable states. In a stable system, robustness is likely to refer to an inherent capacity to recover or reorganise. Systems have one or more stable steady states, or equilibria, towards which systems will return after disturbances. We will refer to this system behaviour as 'adaptation'. In an essentially unstable system, robustness relates to external control measures to protect desired states, presuming a necessity of continuous supervision and regulation. We will refer to this way of coping with disturbances as 'control'. Ten Napel et al. (2006) make a similar distinction between a traditional 'control model' and a presumed, more robust 'adaptation model'. In their view the difference between the two models lies in the ability of systems to cope with disturbances independently, and the changeability incorporated into the system's design. The 'control model' suggests that the system needs human support to maintain its function. Adaptability, on the other hand, refers to a system's capacity to adapt successfully to changing environments. Under the 'adaptation model', the system steady state is typically viewed as an equilibrium: a sphere at the bottom of a cup or valley. Not only does this suggest that it is hard to disturb the system, it also suggests that the system will easily and naturally return to its stable position at the bottom of the cup. These differences in perception of system behaviour suggest that this behaviour is a second organising principle in a robustness framework.

\section{Perception of relation between a system and its environment}

It has been argued that relational views between a system and its environment can be static or dynamic, depending on how the underlying forces which shape disturbances and system reactions are understood.

Especially in ecology, systems are understood as operating in a dynamic relation with their environments (Carpenter and Brock, 2008; Levin and Lubchenco, 2008; Walker et al., 2005; Webb and Levin, 2005). When relations between a system and its environment are static, robustness relates to known and predictable perturbations, while in dynamical relations robustness becomes increasingly connected to unpredictable changes in system variables and environmental dynamics. Although this distinction is highly relevant in analyses of complex adaptive systems, it is of lesser importance for an analysis of system robustness in man-made agricultural production systems. We do therefore not include the distinction between static and dynamic system approaches as an organising principle.

Based on these principles, we can construct a conceptual framework of robustness, consisting of four quadrants that represent potential conceptualisations of robustness. We use bipolar dimensions of system robustness as organising principles, meaning that system stability is either related to efficiency of function, or to persistence of functionality, and likewise system behaviour is either control or adaptation. We believe that different conceptualisations of robustness can be reduced to different combinations of dimensional 
descriptions, for instance Efficiency - Control (EC) or Efficiency - Adaptation (EA).

The organising principles thus generate a framework consisting of dimensional descriptions that represent what we believe are four different robustness conceptualisations. To underline differences we use synonyms of robustness meanings (robustness as...) to refer to these conceptualisations (see Table 1).

Although embedded in system thinking, the framework is not a system taxonomy, but only meant as an overview of different meanings given to robustness. Note that for its construction we have used organising principles related to different interpretations that have been given to robustness, rather than principles to organise different systems.

\section{Table 1. A framework of robustness in dimensional descriptions.}

\begin{tabular}{ll}
\hline Dimensional description & Robustness as \\
Efficiency, Control (EC) & Reliability / insensitivity \\
Efficiency, Adaptation (EA) & Resilience (elasticity) \\
Persistence, Control (PC) & Continuity / applicability \\
Persistence, Adaptation (PA) & Resilience (amplitude) \\
\hline
\end{tabular}

\section{Conceptualisations of robustness}

In the next section we will describe each conceptualisation of robustness in more detail.

\section{Efficiency - control}

A combination of a view of stability focusing on efficiency of function and a relation between a system and its environment requiring external control is typical for engineered systems, in which robustness refers to functional reliability of - independent - system components in the presence of predictable chances of failure. Robust design typically aims to reduce uncertainty in system responses and to satisfy predetermined sets of performance requirements, despite exogenous variability (Allen et al., 2006; Willinger and Doyle, 2005).

Many strategies to create functional reliability may be distinguished, including the use of redundant components and design for reduced sensitivity.

\section{Application}

Redundant components. Redundancy is the duplication of critical components, possibly in combination with majority voting systems, with the intention of increasing the reliability of a system. The basic idea behind engineered redundancy is that a failure in one component, does not lead to total system failure. Consider, for example, multiple modular redundancy in Fly-by-Wire (FBW) control systems. FBW control systems generally consists of three or four independent and differently designed modules in order to prevent common mode failure and a loss of signals when one or even two modules break down. The combination of diversity (different design), modularity (functional independence) and redundancy (duplicates of functionality) significantly reduces the probability of failure under expected levels of environmental variation.

Reduce sensitivity. Since many factors that affect a system cannot be controlled in actual applications - ambient temperature, humidity, etc. - various studies have suggested the creation of robustness by selecting parameters that are less susceptible to variations (Robinson et al., 2004; Roy, 2001; Taguchi, 1986, 1995; Taguchi et al., 1999). This approach was termed quality engineering (Taguchi, 1986), but is more commonly known as the Taguchi approach. The ultimate goal of the Taguchi approach is a quality design that is immune to the influence of uncontrollable noise factors. It is assumed that this can be achieved by properly choosing the levels of controllable factors once desired quality levels have been achieved. The approach thus aims to achieve optimal conditions for quality consistence. It is based on a philosophy of prevention and a strong belief that robustness problems should be tackled at source and not through additional control measures such as inspection and screening. Taguchi's design method has cost-benefit advantages over modular redundant systems and has led to an increased understanding that choices made in early phases of design have a disproportionately large impact on design outcomes such as costs and quality (Allen $e t$ al., 2006; Clausing and Frey, 2005; Jugulum and Frey, 2007).

\section{Benefits and shortcomings}

When trying to create robust products or processes, engineers tend to focus on tightly controlling manufacturing processes to optimise trade-offs between cost and quality. In agriculture, this has led to production systems with high animal concentrations, low labour requirements, high levels of automation, and protective environments in which production is stabilised at maximum levels by keeping disturbances away from crops and animals. Policies 
that rely on this view not only impose few limitations to control and manipulate crops and livestock, but they also encourage human control and domination to keep balance, thus focusing on reliable controlling measures, rather than on the inherent robustness of the production system. These controlling measures appeared to go hand in hand with problems of efficacy and with negative side-effects such as freak accidents, chronic stress and the overburdening of animals, soil degradation, emerging pests, weed and disease problems, which may all have dramatic consequences. New system designs can reduce sensitivity to variation caused by noise factors, but do not necessarily reduce the intensity of control measures. Moreover, focussing on a particular system's sensitivity to noise may shift attention away for hierarchical interactions that underlie unexpected events. In other words, this approach loses attractiveness when uncertainty increases and the need to maintain adaptive capacity is high.

\section{Efficiency - adaptation}

In contrast to control strategies, adaptation strategies try to reduce the consequences of variation by managing, rather than eliminating, their sources. Ten Napel et al. (2006) argue that agricultural production systems should be designed accordingly; they should be able to return to optimal 'original' positions after a disturbance.

According to this view, robustness is measured in terms of elasticity. It concentrates on the stability of systems in the vicinity of steady states of equilibrium and refers to both a resistance to change and to a system's rate of recovery after disturbance. In ecology, it is also known as engineering resilience or the Pimm definition of resilience (Holling, 1996; Holling and Meffe, 1996; Pimm, 1984; Tilman and Downing, 1994).

\section{Application}

Examples of robustness as elasticity are found in homeostatic control systems, where it relates to the regaining of efficiency of function by means of feedback loops and regulation systems. In dairy farming, consider the rate of return to positive energy balance after energy balance nadir (lowest energy balance) during early lactation. Pollott and Coffey (2009) argue that a return to positive energy balance, the level of nadir and the rate of return are important features affecting a cow's luteal activity and day of first heat. Selection for high milk production may have reduced the capacity of lactating cows to regain positive energy balances. In plant sciences, an example of robustness as elasticity is found in the relation between temperature and the recovery of photosynthetic efficiency (Sowinski et al., 2005). Maize is for instance considered less robust in temperate climates since the times needed to attain maximal growth speeds after a temperature shock are longer in temperate climates than in tropical climates. Note, however, that robust plants in terms of elasticity are not necessarily less sensitive to the disturbances from which they easily recover (see for instance Kamoshita et al., 2004).

\section{Benefits and shortcomings}

This conceptualisation of robustness is useful when referring to a system's resistance to change and its recovery capacity. It is used at animal and crop level to assess their capacity to function in sub-optimal conditions. In situations where this conceptualisation of robustness is used, it is suggested that environmental conditions cannot be controlled and disturbances cannot be avoided. Hence, the efficiency of the system depends on the inherent capacity of the system under consideration to cope with variations and disturbances encountered. Many animals and crops have developed an inherent capacity to resist change and cope with unexpected events. Selectively making use of these capacities can contribute to robust production systems. However, trade-offs have been discovered between production and robustness features. As energy invested in the maintenance of coping capacities cannot be utilised for production, high yield varieties which satisfactorily cope with sub-optimal conditions and unexpected events are rare.

\section{Persistence - control}

Persistence-conceptualisations take robustness not as the efficiency of function, but as the maintenance of functionality, or the capacity to maintain a particular state of balance. The control model assumes that these states are unstable but manipulative. As a measure for the capacity to remain balance, the control model takes robustness as the ability to remain structurally unchanged. In dynamic environments, this conceptualisation may extend to the range of system effectiveness.

\section{Application}

Robust structural design. Some systems are meant to remain unchanged, in the sense of being built for eternity or designed against structural failure. Consider the World Trade Centre, that was designed to withstand the 
impact of a Boeing $707^{1}$. In relation to structural design, robustness refers to a system's capacity to withstand extreme circumstances, such as fire or earthquakes and is commonly associated with risk analysis. In contrast to engineering against functional failure, robust structural design does not depend on additional safety measures or passive protection, but on inherent resistance instead (Lamont et al., 2006). Building for eternity is an attempt to realise structural failure avoidance. Systems that are built to remain cannot adapt, intervene or control their existence. In other words: structurally, these systems are static and the only alternative state they can be in is a state of not-being. Note that the function of such systems may nonetheless change dramatically over time, e.g. ancient temples becoming tourist attractions, churches becoming mosques, schools becoming care-centres and factories becoming museums. For these systems, robustness is related to a continuation of existence, or an avoidance of not-being, regardless of the function it fulfils and without necessary interventions.

Flexible modes of operation. Robustness Analysis aims to preserve potentially fruitful options when future conditions are uncertain, future performance is expected to be influenced by uncontrollable future developments and when future evaluation criteria are uncertain or likely to change (Best et al., 1986; Driouchi et al., 2009; Rosenhead, 1980). Policy changes may for instance initiate transitions of all kinds. In operation research literature, robustness refers to the flexibility that an initial decision of a plan maintains in order to achieve near-optimal states in conditions of uncertainty (Rosenhead et al., 1972). Consider the ability of a particular trading strategy to stay effective in different markets and under varying market conditions, or the potential of a production strategy to stay socially acceptable in different societies and under changing moralities. In these situations, robustness is a supplementary criterion for the choice of an initial decision, and it is intrinsic because it exists as a by-product of selection for a specific strategy, rather than as a target in itself. One could say that robustness here relates to the range of system effectiveness.

\section{Benefits and shortcomings}

Robust structural design has value only for the structural elements of agricultural systems. Housing systems for instance should be designed to withstand forces that can be reasonably expected as to avoid structural failures. As an

\footnotetext{
${ }^{1}$ BBC News, March $7^{\text {th }} 2002$ suggested that the WTC exclusively collapsed because of the fuel on board the hijacked Boeing $767 \mathrm{~s}$ that were used in the 9-11 attacks. See also http://news.bbc.co.uk/2/ hi/science/nature/1858491.stm.
}

operationalisation of sustainability, improving the structural robustness of agricultural systems has limited value. The second application, referring to system effectiveness and the preservation of flexibility, proceeds from the idea that future conditions are uncertain and likely to change. This application has implicit, but strategic relevance for sustainable development studies. We consider this view as a recommendation to relate robustness to the composition of a stock of options, rather than to an 'all-or-nothing' solution and invest in the flexibility and preservation of these options. As a shortcoming of this approach, we observe that robustness is seen as a supplementary criterion, rather than as a guiding principle in the initial decision. As an image of sustainability, this conceptualisation lacks tangibility and measurability.

\section{Persistence - adaptation}

A more adaptive view conceptualises robustness in terms of resilience, concentrating on the ability of particular sets of organising structures and processes to persist in the vicinity of thresholds (Holling, 1973; Levin and Lubchenco, 2008; Walker et al., 2005). Unlike resilience studies which focus on the resistance to disturbance and the speed of recovery in the vicinity of steady states of equilibrium (section above), this view focuses on conditions far from steady states of equilibrium and the corresponding instabilities that may cause transition towards alternative steady states (Holling et al., 2002). This view is known as 'ecosystem resilience' (Holling, 1996; Holling and Meffe, 1996). Ecosystem resilience is not related to the rate at which a system returns to equilibrium, but rather to the maximum magnitude of disturbance which a system can absorb before its structure changes. Ecosystem resilience measures the amount of space in which a particular configuration can persist, or its susceptibility to being transformed to an alternative configuration by stochastic events. The concept was developed in regard to ecosystems and referred specifically to the preservation of their ability to function in the presence of external pressure (Holling, 1973). The idea of systems alternating between stationary stable states has been worked out in many different fields outside ecology. It is an adaptive view in the sense that policies and management approaches can influence the internal dynamics which systems experience.

\section{Application}

This conceptualisation takes robustness as the magnitude of disturbance which a system can absorb before its structure changes and suggests that system robustness is determined by the dynamic interactions of various processes at different 
periodicities and spatial scales. This idea was worked out in detail by Gunderson and Holling (2002), who introduced the term panarchy to 'capture the adaptive and evolutionary nature of adaptive cycles that are nested one within the other across time and space scales'.

The idea of panarchies has mainly been applied to ecological and social-ecological systems (SES), the robustness of which is usually referred to as social-ecological resilience. A social-ecological system is a complex system that incorporates human societies, ecosystems, and their interactions (Cumming, 2011). SES studies recognise that human societies not only depend on natural resources for exploitation, but consequently also modify these resources.

Anderies et al. (2004) therefore argue that SES are robust if they successfully prevent 'the ecological system upon which the social component relies [moving] into a new domain of attraction that cannot support a human population, or that will induce a transition that causes long-term human suffering'. In other words, a robust SES is sustainable because it stays on track, or continues to succeed in finding sufficient resources to exploit for its maintenance. Robustness then relates to the preservation of resilience and persistence in the history of life, rather than to the resilience of the system against a specific perturbation per se.

\section{Benefits and shortcomings}

This conceptualisation combines some of the views discussed above, but adds a feature characteristic for social systems, namely the capacity to anticipate and plan for the future, which makes it relevant from a perspective of sustainable development. Although the term robustness is in use for this idea, it is more commonly referred to as ecosystem resilience. This conceptualisation also challenges the dominant 3BL approach of sustainability, since it rejects the ideals of stability based on static assumptions such as maximum sustainable yield and carrying capacity that are typically related to $3 \mathrm{BL}$ sustainability. Instead, the sustainability approach of ecological resilience thinking is based on continuous change at various system levels, suggesting that sustainability cannot be considered as preserving a status quo, but is only achieved through adoption and evolution, whether or not through radical reorganisation. This approach is in keeping with the science of complexity which aims to explain non-linearity and unpredictability in complex system dynamics. We observe that the increasing interest in complexity studies within the agricultural sciences undermines the $3 \mathrm{BL}$ sustainability paradigm.

\section{TransForum project 1: stacking functionality expressed in apple genes}

\section{Objective and background}

The aim of this project was the development of high-quality apple varieties that have a durable resistance to apple scab (Venturia inaequalis). The dominant idea behind this project was that durable resistance to apple scab allows a strong reduction in fungicide usage in apple growing. This idea will perhaps contribute to a sustainable development of apple production in north-western Europe and makes it possible to position apple production in or near urban areas, where city dwellers can enjoy the beauty of flowering and fruiting orchards.

To achieve durable resistance, the project aimed to stack two resistance genes isolated from resistant apple plants that have an insufficient fruit quality, and introduce them into elite high-quality varieties by means of cisgensis, genetic modification with species-specific genes only. This procedure is much faster than conventional breeding. The initiators argued that conventional breeding could lead to the same results, but that the goals to reduce chemical input the agricultural sector has jointly formulated with the Dutch government do not allow four or five decades of conventional breeding. For more information on this project, and an overview of publications, see: http://www.transforum. $\mathrm{nl} /$ projecten/wetenschappelijke-projecten/item/47-stapelingvan-genen-voor-duurzame-resistentie-tegen-appelschurft

\section{Sustainability approach}

The sustainability approach is mainly social-economical. Two sustainability problems are highlighted in the project.

- Economic viability. Due to import from other parts of the world, apple cultivation in the Netherlands and northwestern Europe is generally not economically viable.

- Social-ecological conditions. The present high-quality cultivars are susceptible to apple scab, and therefore require approximately 15 chemical sprays per year, however the aim is to reduce the chemical input. It is suggested that high-quality cultivars with durable resistance to apple scab are urgently needed in order for the fruit growers to survive. Hence, economic sustainability is considered within socio-ecologically limiting conditions. The desired integration of fruit growing and living areas the initiators have in mind would indicate that these limiting conditions are met. 


\section{Conceptualisation of robustness and contribution to sustainable farming}

To achieve the above sustainability goals, the project aimed to develop a more durable resistance strategy at plant level, i.e. robust apple varieties. It is suggested that such robustness requires at least two functionally expressed resistance genes, stacked in a variety. This is called gene pyramiding, or gene stacking. The project uses genetic modification to stack two apple scab resistance genes in susceptible elite cultivars with superior fruit quality to provide these varieties with durable resistance to scab. Stacking genes through genetic modification to create durable resistance is an innovative approach which can be applied to all other crops, without the necessity of time-consuming breeding programs.

Polygene resistant varieties are expected to maintain their resistance longer than monogenic resistant varieties, since the pyramiding of resistance genes creates redundancy. This strategy shows remarkable similarities with the use of modular redundancy as applied in Fly-By-Wire Control Systems in aeronautical engineering, for instance. Where the use of different groups of computers, based on different hardware and equipped with different software has considerably reduced the risk of aircraft loss due to flight control failure, the pyramiding of resistance genes intentionally combines parallel and independent resistance genes to increase overall resistance, including a back-up system in case one of the resistance genes is overcome. In the dimensional description that we suggest, this project conceptualised robustness at the plant level as a combination of efficiency and control. On a social level, the project anticipated social-ecological and socialeconomic developments such as dynamic market shares, taste preferences and the social acceptance of chemical input versus the use of genetic modification.

\section{TransForum project 2: SynErgie: a monitoring and control system for conditioning of plants and greenhouses}

\section{Objective and background}

Stimulated by high energy prices, new greenhouses are being developed which will only need a small fraction of the energy they need today or will even be net producers of energy. These energy-poor and energy-producing greenhouses have a completely different type of climate than conventional greenhouses. So far, the SynErgie project has identified a number of barriers that obstruct the development of energy-producing greenhouses. A major bottleneck for this invention is how to monitor and control the crop in these greenhouses. It is suggested that a new method of growing plants, called conditioned growth, is needed to successfully reduce energy use by the greenhouse industry, while further optimising the production of vegetables, cut flowers and pot plants. The project continues to aim to quantify physiological effects on plants of new climate conditions such as high air humidity under summer conditions, and develop intelligent crop monitoring systems of plant performance. For more information on this project, and an overview of publications, see: http://www.transforum.nl/ projecten/wetenschappelijke-projecten/item/55-synergiegewas-van-de-toekomst-in-kas-van-de-toekomst

\section{Sustainability approach}

This scientific project has contributed to the invention of an energy-producing greenhouse in combination with a very high and controllable production. It is argued that this has ensured the competitiveness of the greenhouse horticultural sector for the future. Although energy reduction has ecological benefits, the sustainability approach of this project has mainly been economic. High energy prices, rather than ecological limitations, impose energy reduction on the horticultural sector. Physiological limitations of crops and necessary crop monitoring systems are the main barriers which obstruct the development of energy-producing greenhouses.

\section{Conceptualisation of robustness and contribution to sustainable farming}

This project relates to a specific form of robustness at the level of a cropping system and individual plants. It has thus far aimed to create a cropping system which optimises production under the very specific growth conditions of energy-producing greenhouses by continuous monitoring and adapting. This optimisation consists of an iterative process of technological innovation and crop physiology. Although not explicitly expressed, the project has taken the inherent robustness range (plant requirements) of the plants as a starting point for the design of new greenhouses. The results of this study aim to give insight into the quantitative effects of new climate conditions on crop performance and should not only make clear which critical plant processes must be monitored, but also give direction to the development of novel optimisation procedures and adaptations of greenhouse design. The project has thus contributed to both a redefinition of desired quality levels within the new greenhouses, and the optimisation of controllable levels therein to promote consistent high-quality production and reduce the influence of uncontrollable noise factors. To make conditioned growth 
possible, it has been argued that the plants should be 'vandal-proof' to be able to cope with expected deviations from optimal growth conditions. Concentrating on the stability of crop production in near-optimal conditions, robustness is conceptualised at the plant level in terms of resistance to change or engineering resilience. At cropping system level, it is used as a parameter to design reliable monitoring and control systems. Here, robustness relates to reliability. In the dimensional description that we suggest, this project conceptualises robustness in terms of efficiency and control.

\section{TransForum project 3: robust animal production}

\section{Objective and background}

The main objective of this project was to develop the concept of robustness of animal production systems at various levels using system and control theory and apply these concepts to cases in the production system (farm), the production chain and at regional level. The starting point for the project was a working paper by Ten Napel et al. (2006) discussing two approaches on achieving stability in agricultural production systems. The prevailing approach, which is called the 'Control Model', is to protect crops and livestock from disturbances as much as possible, to regain balance with monitoring and intervention and to look for add-on solutions only. The alternative model, called the 'Adaptation Model', is based on reducing the consequences of disturbances, rather than preventing. Ten Napel et al. argued that this means utilising and supporting the intrinsic robustness of crops and livestock, i.e. their capacity to deal with disturbances by adaptation. For more information on this project, and an overview of publications, see: http:// www.transforum.nl/projecten/wetenschappelijke-projecten/ item/54-robuustheid-bij-dierlijke-productiesystemen.

\section{Sustainability approach}

In the context of robustness, this project defined a sustainable animal production system as an animal production system which is able to maintain its functionality and/or its form in a set time interval, whereby system components need not be maintained. To assess sustainability, the 3BL approach was used. The project defined robustness as a means to achieve the stability of specific sustainability aspects, either in space or in a certain time scale. Robustness deals, amongst other things, with stability of production systems, or more precisely, stability in time and space of measurable indicators defined by means of a sustainability analysis.

\section{Conceptualisation of robustness and contribution to sustainable farming}

For the relation between robustness, stability and sustainability, robustness is seen to connect sustainability to system stability, i.e. to contribute to the preservation of a desired, sustainable steady state. While sustainability is described as maintaining functionality, robustness is explicitly related to achieving stability of production-related sustainability aspects in time and space. Especially since the project clearly proposed that 'Robustness deals with the stability of measurable indicators that are defined by means of a sustainability analysis', it becomes clear that the system-stability view behind this project was ultimately based on efficiency of function. The project relied on control theory to achieve consistent, optimised production in animal production systems, but rejected the traditional role of engineering as aiming to control variation. Instead, it built on the 'adaptation model' (Ten Napel et al., 2006) to reduce the consequences of uncontrollable fluctuations and discover novel ways to create order in animal production systems.

This project focused on robustness at the level of herd, production chain and landscape, and not at the animal level, although it sought to utilise robustness at the animal level for robustness at higher levels. One of the main goals of the project was to make sustainability of production systems more operational by developing the concept of robustness, from a system-theory perspective. The project was positioned as an interdisciplinary project between two major disciplines, i.e. measurement and control theory, and animal production systems. Following the vision that the robustness of systems is basically a control problem (how are output or internal state variables kept within preset limits?), the project assumed that control theory can be applied and used to make animal production systems more robust, i.e. less sensitive to unwanted fluctuations. Robustness was thus here explicitly seen as a designable system feature. By integrating social and environmental considerations into the system design, it aimed at reducing sensitivity to unwanted variations which can be expected under normal conditions. All in all, the sustainability approach and operationalisation of robustness therein has a strong focus on people and profit.

In the dimensional description that we suggest, this project conceptualised robustness as a combination of efficiency and control; a condition in which the production process is insensitive to variation in individual factors. 


\section{Discussion}

Our analysis of the three TransForum projects which operationalised robustness suggests that in all the projects robustness was or has been narrowly used to refer to the efficiency of the function of systems and in relation to control. In this section, we return to the suggested frame of reference and discuss the relevance of conceptualisations used, as well as alternative conceptualisations of robustness in agriculture.

In the TransForum projects, as well as in other agricultural contexts, engineering conceptualisations of robustness such as reliability or insensitivity (see section 3 ) appear dominant, not only with regard to control and monitoring systems in advanced greenhouses, but also with regard to livestock and crop systems, where robustness is generally considered at animal or crop level. It is relevant from an engineering and efficiency perspective, in which solutions are being sought for relatively well-defined sustainability problems in relatively well-defined systems. It is an approach that relies on the predictability of fluctuations and the corresponding chances of failure.

The second conceptualisation, a combination of efficiency and adaptation is attractive, but trade-offs between adaptive capacity and efficiency have been found. This conceptualisation seems useful when relatively low productivity is acceptable or the costs of efficiencymaintaining control measures are too high. However, designing for adaptation ultimately leads to increased control at the operational management level. Whenever the adaptive capacity of systems becomes a target of design, it becomes planned, and purposefully placed under care of the farmer. Planned adaptation is essentially different from associate adaptive capacity which contributes to system robustness independently of the farmer's planning, just as planned diversity such as the variety of crops and animals is essentially different from associate biodiversity. Planned adaptation and diversity have become part of the operational management of the system, and thus make adaptive capacity or diversity an element of control. While associate adaptation has a structural value, planned adaptation has a functional value, since it has relevance only in relation to the (long-term) efficiency of the system and obtains its value as a rational choice (Vandermeer, 2011). This is also our main critique of Ten Napel et al.'s adaptation model (2006). The adaptation model suggests that adaptive capacity can be increased with control theory, i.e. controlled adaptation. Rather than reducing the intensity of control on the system, the adaptation model adds adaptive capacity to the existing control model.
The Persistence - Control conceptualisation of robustness was developed in structural engineering as well as strategic decision support. The TransForum projects discussed do not suggest that this conceptualisation has direct relevance in agricultural contexts. However, the relevance of this conceptualisation is merely implicit. Consider the idea behind TransForum Project 2 in which the desire to sustain apple production in Western Europe requires strategic decisions to design production methods which are effective despite unknown political decisions. The effectiveness of the suggested solution ultimately depends on the exemption of cisgenesis from the existing regulations on genetic modification. Recognising that current production methods may have reached the limits of applicability, the suggested alternative lacks flexibility in its modes of operation, since it seeks a solution to the side-effects of existing production methods, rather than strategically preserving potentially fruitful options. In other words, the cisgenic apple has no near-optimal state: it is an 'all-or-nothing' solution. If one takes into account that cisgenesis is, at this moment, not even permitted by European regulations, one must conclude that the applicability conceptualisation of robustness is extremely relevant for this project. As an operationalisation of sustainability, this robustness conceptualisation is relevant because it stresses the importance of considering the flexibility of a decision to achieve near-optimal states when future circumstances depend on developments outside one's own control.

The fourth robustness conceptualisation, namely the ecological resilience view, is largely ignored in agricultural innovation projects. This conceptualisation has developed in complexity theory, and is particularly relevant in relation to so-called complex adaptive systems. Similar to the applicability conceptualisation of robustness, this view has implicit relevance, but particularly at high abstraction levels. That is due to the fact that it is assumed that agricultural systems operate in complex adaptive systems: socialecological systems in which agriculture is a disturber, rather than a vulnerable. System robustness thus extends the level of the agricultural sub-system, and increasingly relates to the impact of resource modification agriculture has on the absorbing capacity of the ecological system in which it is practiced. This view stresses that the social and economic components of sustainability rely on the ecological system and it is therefore at odds with the 3BL sustainability approach that was endorsed in the TransForum Project. Operationalisation of this view of robustness in agricultural innovation projects would require a reconsideration of the epistemic methods that constitute sustainability as an object of science. We believe that the added value of this view is the insight that agricultural practices can lead 
to collapsing ecosystems and a reduction in exploitable resources. The examples are many that whereas $3 \mathrm{BL}$ is a noble endeavour, ecological resilience is an inevitability. Our ability to measure and understand the non-linear dynamics underlying ecological resilience is limited, but slowly increasing. Future assessments of agricultural sustainability cannot side-step this operationalisation of robustness.

\section{Conclusion}

We suspect that TransForum's intial choice to endorse the 3BL approach to stimulate sustainable development explains why robustness has been conceptualised in terms of efficiency and control. We observe that the $3 \mathrm{BL}$ approach is scientifically disputed since it enhances the quantitative measurement of sustainability aspects and subsumes environmental and social concerns therein, and it is particularly criticised for its inability to include normative values in the metrics it uses (Gibson, 2011).

Recently, KPMG International (KPMG, 2012) urged businesses around the world to apply systems thinking in their sustainability strategies and develop resilience, flexibility and adaptive capacity to prepare for the unexpected, rather than focusing on measurable risks and probabilities. This call connects with some of the robustness conceptualisations - not yet applied in agricultural contexts - which we found in our analysis, most notably those related to persistence of functionality.

We believe robustness has the potential to function as an image of sustainability in agriculture. As yet, the concept has been narrowly used to refer to improved efficiency and increased controllability of engineered systems, thereby largely ignoring that robustness is embedded and has particularly evolved in complex adaptive system thinking. Considering the growing interest in complex (adaptive) systems and alternative system approaches (Darnhofer $e t$ al., 2010a,b) within the agricultural sciences, it is time to reconsider the meaning of robustness vis-a-vis sustainable agriculture.

\section{Acknowledgements}

This study was financially supported by TransForum, initiated and partly funded by the Dutch Government to contribute to a more sustainable and innovative knowledge infrastructure in agriculture. We thank the anonymous reviewers for their comments on an earlier version of this paper.

\section{References}

Allen, J.K., C. Seepersad, H.J. Choi, and F. Mistree, 2006. Robust design for multiscale and multidisciplinary applications. Journal of Mechanical Design, 128 (4): 832-843.

Anderies, J.M., M.A. Janssen, and E. Ostrom, 2004. A framework to analyze the robustness of social-ecological systems from an institutional perspective. Ecology and Society, 9 (1): 18.

Aronson, D., 1996. Overview of systems thinking. Available at: http:// www.thinking.net/Systems_Thinking/systems_thinking.html.

Best, G., G. Parston and J. Rosenhead, 1986. Robustness in practicethe regional planning of health services. The Journal of the Operational Research Society, 37 (5): 463-478.

Carpenter, S.R. and W.A. Brock, 2008. Adaptive capacity and traps. Ecology and Society, 13(2): 40.

Cittadini, E.D., M.T.M.H. Lubbers, N. de Ridder, H. van Keulen and G.D.H. Claassen, 2008. Exploring options for farm-level strategic and tactical decision-making in fruit production systems of South Patagonia, Argentina. Agricultural Systems, 98 (3): 189-198.

Clausing, D.P. and D.D. Frey, 2005. Improving system reliability by failure-mode avoidance including four concept design strategies. Systems Engineering, 8(3): 245-261.

Cumming, G.S., 2011. Spatial resilience in social-ecological systems. Springer Science+Business Media B.V., Dordrecht, the Netherlands.

Darnhofer, I., S. Bellon, B. Dedieu and R. Milestad, 2010a. Adaptiveness to enhance the sustainability of farming systems. A review. Agronomy for Sustainable Development, 30(3): 545-555.

Darnhofer, I., J. Fairweather and H. Moller, 2010b. Assessing a farm's sustainability: Insights from resilience thinking. International Journal of Agricultural Sustainability, 8(3): 186-198.

Driouchi, T., M. Leseure and D. Bennett, 2009. A robustness framework for monitoring real options under uncertainty. Omega, 37(3): 698-710.

Gibson, K., 2011. The fungible and the sacred: reimagining the triple bottom line for sustainability. The International Journal of Environmental, Cultural, Economic and Social Sustainability, 7(4): 133-144.

Gilbert, A.J., 2009. Connectance indicates the robustness of food webs when subjected to species loss. Ecological Indicators, 9(1): 72-80.

Holling, C.S., 1973. Resilience and stability of ecological systems. Annual Review of Ecology and Systematics, 4: 1-23.

Holling, C.S., 1996. Engineering resilience versus ecological resilience. In: Schulze, P.C. (ed.), Engineering within ecological constraints. National Acadamy Press, Washington, DC, USA, pp. 31-43.

Holling, C.S. and L.H. Gunderson, 2002. Resilience and adaptive cycles. In: Gunderson, L.H. and C.S. Holling (eds.), Panarchy, understanding transformations in human and natural systems, Island Press, Washington DC, USA, pp. 25-62. 
Holling, C.S., L.H. Gunderson and D. Ludwig, 2002. In quest of a theory of adaptive change. In: Gunderson, L.H. and C.S. Holling (eds.), Panarchy: understanding transformations in human and natural systems, Island Press, Washington DC, USA, pp. 3-22.

Holling, C.S. and G.K. Meffe, 1996. Command and control and the pathology of natural resource management. Conservation Biology, 10(2): 328-337.

Jen, E. (ed.), 2005. Robust design: a repertoire of biological, ecological, and engineering case studies, Oxford university press, Santa Fe Institute, USA, 285 pp.

Jugulum, R. and D. Frey, 2007. Toward a taxonomy of concept designs for improved robustness. Journal of Engineering Design, 18(2): 139-156.

Kamoshita, A., R. Rodriguez, A. Yamauchi and L.J. Wade, 2004. Genotypic variation in response of rainfed lowland rice to prolonged drought and rewatering. Plant Production Science, 7(4): 406-420.

Kanis, E., K.H. De Greef, A. Hiemstra and J.A.M. van Arendonk, 2005. Breeding for societally important traits in pigs. Journal of Animal Science, 83(4): 948-957.

Kanis, E., H. Van den belt, A.F. Groen, J. Schakel and K.H. De Greef, 2004. Breeding for improved welfare in pigs: A conceptual framework and its use in practice. Animal science, 78(2): 315-329.

Kitano, H., 2007. Towards a theory of biological robustness. Molecular Systems Biology, 3: 1-7.

Klopčič, M., R. Reents, J. Philipsson, and A. Kuipers (eds.), 2009. Breeding for robustness in cattle, Wageningen Academic Publishers, Wageningen, the Netherlands.

Knap, P.W., 2005. Breeding robust pigs. Australian journal of experimental agriculture, 45(7-8): 763-773.

KPMG, 2012. Expect the unexpected: building business value in a changing world. KPMG International, Switzerland. Available at: http://www.kpmg.com/Global/en/IssuesAndInsights/ ArticlesPublications/Documents/building-business-value.pdf.

Lamont, S., B. Lane, A. Jowsey, J. Torerro, A. Usmani and G. Flint, 2006. Innovative structural engineering for tall buildings in fire. Structural Engineering International: Journal of the International Association for Bridge and Structural Engineering (IABSE), 16(2): 142-147.

Lesne, A., 2008. Robustness: confronting lessons from physics and biology. Biological Reviews, 83(4): 509-532.

Levin, S.A. and J. Lubchenco, 2008. Resilience, robustness, and marine ecosystem-based management. Bioscience, 58(1): 27-32.

Levy, S.F. and M.L. Siegal, 2008. Network Hubs buffer environmental variation PLoS Biology, 6(11): 2588-2604.

Lien, G., J. Brian Hardaker and O. Flaten, 2007. Risk and economic sustainability of crop farming systems. Agricultural Systems, 94(2): 541-552.

LNV, 2007. Nota Dierenwelzijn. Ministerie van Landbouw, Natuur en Voedselkwaliteit, Den Haag, the Netherlands.

Pimm, S.L., 1984. The complexity and stability of ecosystems. Nature, 307(5949): 321-326.
Pollott, G.E. and M.P. Coffey, 2009. The link between energy balance and fertility in dairy cows. In: Klopčič, M., R. Reents, J. Philipsson and A. Kuipers (eds.), Breeding for robustness in cattle, Wageningen Academic Publishers, Wageningen, the Netherlands, pp. 207-218.

Robinson, T.J., C.M. Borror and R.H. Myers, 2004. Robust parameter design: a review. Quality and Reliability Engineering International, 20(1): 81-101.

Rosenhead, J., 1980. Planning under uncertainty: II. a methodology for robustness analysis. The Journal of the Operational Research Society, 31(4): 331-341.

Rosenhead, J., M. Elton and S.K. Gupta, 1972. Robustness and optimality as criteria for strategic decisions. Operational Research Quarterly (1970-1977), 23(4): 413-431.

Roy, R.K., 2001. Design of experiments using the Taguchi approach: 16 steps to product and process improvement, Wiley, New York, NY, USA.

Sall, S., D. Norman and A.M. Featherstone, 1998. Adaptability of improved rice varieties in senegal. Agricultural Systems, 57(1): 101-114.

Scharloo, W., 1991. Canalization: genetic and developmental aspects. Annual Review of Ecology and Systematics, 22: 65-93.

Sowinski, P., A. Rudzinska-Langwald, J. Adamczyk, I. Kubica and J. Fronk, 2005. Recovery of maize seedling growth, development and photosynthetic efficiency after initial growth at low temperature. Journal of Plant Physiology, 162(1): 67-80.

Star, L., E.D. Ellen, K. Uitdehaag and F.W.A. Brom, 2008. A plea to implement robustness into a breeding goal: poultry as an example. Journal of Agricultural \& Environmental Ethics, 21(2): 109.

Taguchi, G., 1986. Introduction to quality engineering: designing quality into products and processes. Asian Productivity Organization. UNIPUB, White Plain, NY, USA, 191 pp.

Taguchi, G., 1995. Quality engineering (Taguchi methods) for the development of electronic circuit technology. IEEE Transactions on Reliability, 44(2): 225-229.

Taguchi, G., S. Chowdhury and S. Taguchi, 1999. Robust engineering, McGraw-Hill Companies, New York, NY, USA, 241 pp.

Ten Napel, J., F. Bianchi and M. Bestman, 2006. Utilising intrinsic robustness in agricultural production systems. TransForum working papers, no.1, Zoetermeer, the Netherlands, p. 32-54.

Tilman, D. and J.A. Downing, 1994. Biodiversity and stability in grasslands. Nature, 367(6461): 363-365.

Van Latesteijn, H.C. and K. Andeweg, 2011. The TransForum model: transforming agro innovation toward sustainable development, Springer, Dordrecht, the Netherlands.

Vandermeer, J.H., 2011. The ecology of agroecosystems, Jones and Bartlett Publishers, Boston, MA, USA.

Waddington, C.H., 1953. Genetic assimilation of an acquired character. Evolution, 7(2): 118-126. 
Walker, B., G. Peterson, J.M. Anderies, A. Kinzig and S. Carpenter, 2005. Robustness in ecosystems. In: Jen, E. (ed.), Robust design: a repertoire of biological, ecological, and engineering case studies, Oxford University Press, New York, NY, USA, pp. 173-189.

Webb, C.T. and S.A. Levin, 2005. Cross-system perspectives on the ecology and evolution of resilience. In: Jen, E. (ed.), Robust design: a repertoire of biological, ecological, and engineering case studies, Oxford University Press, New York, NY, USA, pp. 151-172.

Willinger, W. and J.C. Doyle, 2005. Robustness and the internet: design and evolution. In: Jen, E. (ed.), Robust design: a repertoire of biological, ecological, and engineering case studies, Oxford University Press, Santa Fe Institute, USA, pp. 231-271.

WUR, 2004. Houden van Hennen - op naar gelukkige kippen, trotse boeren en tevreden burgers, Wageningen UR Projectteam Houden van Hennen Wageningen - Lelystad, the Netherlands, $16 \mathrm{pp}$. 
